\title{
Action of oral metoclopramide on the gastrooesophageal junction in man
}

\author{
J. B. DILAWARI ${ }^{1}$ AND J. J. MISIEWICZ
}

From the Medical Research Council Gastroenterology Unit, Central Middlesex Hospital, London

SUMMARY The effect of oral metoclopramide, $10 \mathrm{mg}$, was studied with intraluminal manometry in 20 patients suffering from symptoms of gastrooesophageal reflux. The drug increased cardiac sphincter pressure and the amplitude of oesophageal peristaltic waves, but gastric motility was stimulated in only half of the patients. The clinical value of these pharmacological effects should be confirmed in therapeutic trials.

Metoclopramide (Maxolon, Primperan) is frequently prescribed for heartburn or regurgitation, the symptoms of gastrooesophageal reflux. Although metoclopramide increases cardiac sphincter pressure in normal people when given intravenously (Heitmann and Möller, 1970), it is not known whether it has a similar effect when given to patients by mouth. We have therefore measured the effect of oral metoclopramide on the pressures in the oesophagus, cardiac sphincter, and the stomach in patients with symptoms of reflux.

\section{Patients and Methods}

Twenty-five patients, all with symptoms of reflux, were studied: brief clinical details are in table I. The

\begin{tabular}{lrllll}
\hline & No. & Men/Women & Radiology \\
\cline { 3 - 6 } & & & Reflux & $\begin{array}{l}\text { Duodenal } \\
\text { Ulcer }\end{array}$ & Negative \\
\hline $\begin{array}{l}\text { Placebo } \\
\begin{array}{l}\text { Metoclo- } \\
\text { pramide }\end{array}\end{array}$ & 5 & $5 / 0$ & 4 & - & 1 \\
\hline
\end{tabular}

Table I Clinical details of patients

patient's informed consent to the test was obtained in each case. Five patients were studied with a placebo, in order to assess the stability of the oesophageal pressures during the two-hour test. The remaining 20 patients received metoclopramide $10 \mathrm{mg}$ by mouth.

${ }^{1}$ In receipt of the Astor Fellowship from the Middlesex Hospital Medical School.

Received for publication 2 March 1973.
Intraluminal pressures were measured with an assembly of four polyvinyl tubes (internal diameter $1.2 \mathrm{~mm}$ ) with side-opening tips $5 \mathrm{~cm}$ apart; the tubes were perfused with water at the rate of $7 \mu \mathrm{l}$ $\mathrm{sec}^{-1}$. Pressures were recorded on a multichannel pen writer. Swallowing was monitored with a pneumograph placed over the larynx. The patients were intubated following an overnight fast. With the patient supine, the tube assembly was positioned so that the two proximal tips were in the oesophagus, the third in the cardiac sphincter, and the fourth in the stomach. The cardiac sphincter was identified as a zone of high pressure which relaxed on swallowing. Pressures were continuously recorded for a basal 30 minutes. The patient then swallowed a tablet of metoclopramide $10 \mathrm{mg}$ (20 patients) or a placebo (lactose $100 \mathrm{mg}$, five patients) with $100 \mathrm{ml}$ of water. The pressures were then recorded for a further 90 minutes.

The pressure tracings were analysed in consecutive 10-min periods. The average cardiac sphincter pressure was calculated in each period as the difference between end expiratory fundal and sphincteric pressures. In each 10-min period the mean amplitude of oesophageal peristaltic contractions and the duration and amplitude of gastric pressure waves were also measured.

The action of metoclopramide on the cardiac sphincter was analysed in three different ways, with each patient acting as his own control. First, the mean sphincteric pressures in the group of patients given the placebo or metoclopramide were compared before and after the drug for each 10-min period, and the differences examined with Student's $t$ test. Secondly, the highest sphincter pressure attained 
after the drug was compared in each patient with his mean basal pressure. Lastly, the onset, duration, and persistence of the drug's action was assessed in each patient in terms of a 'response', which was arbitrarily defined as a rise in cardiac sphincter pressures of $100 \%$ or more above the mean basal level in any $10-$ min period. The value of $100 \%$ was adopted, because although pressures during the basal period were generally stable, they did vary by $50 \%$ from the mean in three of the patients.

\section{Results}

In the five patients given the placebo pressure levels in the oesophagus, the cardiac sphincter, and the stomach showed no consistent changes during the two-hour test (fig 1).

By contrast, the mean pressure in the cardiac sphincter increased in the group of 20 patients given $10 \mathrm{mg}$ of metoclopramide. The increase in mean pressure became apparent approximately $20 \mathrm{~min}$ after the drug and persisted to the end of the study (fig 1). Although the increase in sphincteric pressure was highly significant in comparison with mean basal levels $(P<0.02$ to $<0.001)$, the observed rise in pressure averaged only 6-7 $\mathrm{mm} \mathrm{Hg}$. The relaxation of the cardiac sphincter after swallowing was not affected by the drug.

The highest sphincter pressure observed in each patient during $90 \mathrm{~min}$ following the drug is shown in figure 2. In all the patients except two, cardiac

\section{GARDIAC SPHINGTER}

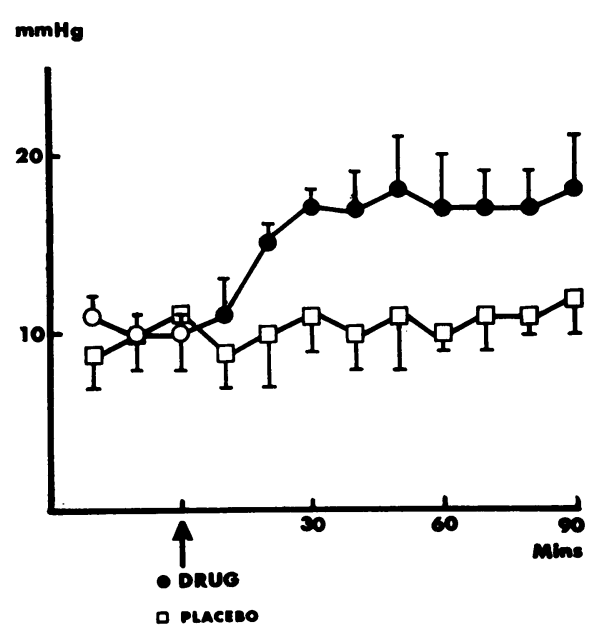

Fig 1 Cardiac sphincter pressures before $(O)$ and after (O) oral metoclopramide ( $n=20$, upper curve), or placebo $(n=5$, lower curve $)$. Symbols show mean $\pm S E M$.

\section{GARDIAC SPHINGTER}

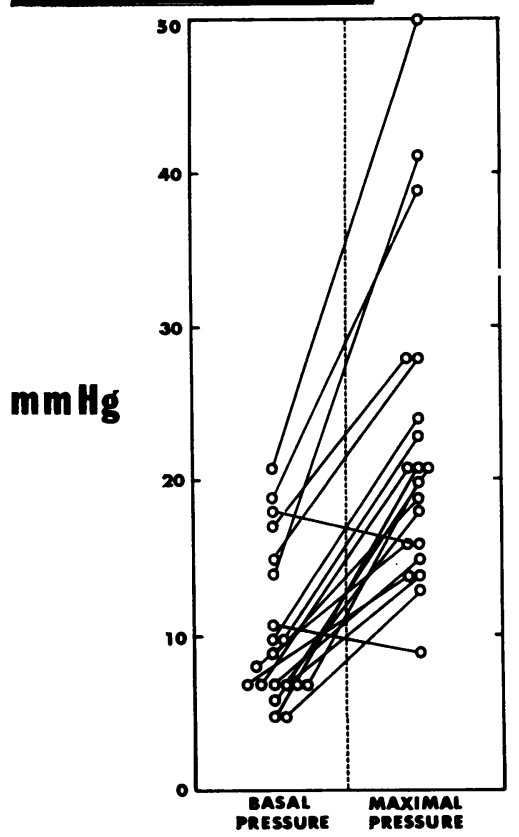

Fig 2 Cardiac sphincter pressures before and after oral metoclopramide in individual patients. Left column: mean basal pressure; right column: maximal pressure attained during 90 min after the drug in any 10-min period.

sphincter pressure increased at some time after metoclopramide. However, the highest pressures were recorded in the patients who had high basal pressures to start with. The time of onset and persistence of the drug's action are shown in terms of the 'response' in figure 3. Analysed in this way, four patients showed no 'response' to metoclopramide during the period of study. In the remainder, the 'response' was observed at 10 to $90 \mathrm{~min}$ after the drug. The duration and persistence of the 'response' were also variable (fig 3 ).

Mean amplitude of oesophageal peristaltic contractions increased by $4-10 \mathrm{~mm} \mathrm{Hg}$ in most 10 -min periods after metoclopramide (table II). Gastric motility was stimulated in half the patients, the remainder being unaffected. No unwanted effects of the drug were observed.

\section{Discussion}

This study shows that $10 \mathrm{mg}$ of oral metoclopramide augments the amplitude of oesophageal peristaltic contractions, raises the cardiac sphincter pressure, and stimulates gastric motility in patients suffering 


(2)

\begin{tabular}{|c|c|c|c|c|c|c|c|c|c|c|}
\hline \multirow{3}{*}{$\begin{array}{l}\text { Site of Tube above } \\
\text { Cardiac Sphincter }(\mathrm{cm})\end{array}$} & \multicolumn{10}{|c|}{ Pressure in $\mathrm{mm} \mathrm{Hg}$ (Means $\pm S E M$ ) } \\
\hline & \multirow{2}{*}{$\begin{array}{l}\text { Average Basal } \\
(30 \mathrm{~min})\end{array}$} & \multicolumn{9}{|c|}{ Minutes after Metoclopramide } \\
\hline & & 10 & 20 & 30 & 40 & 50 & 60 & 70 & 80 & 90 \\
\hline $\begin{array}{r}10 \\
5\end{array}$ & $\begin{array}{l}34 \pm 2 \\
38 \pm 3\end{array}$ & $\begin{array}{l}37 \pm 2 \\
41 \pm 3\end{array}$ & $\begin{array}{l}39 \pm 3 \\
43 \pm 3\end{array}$ & $\begin{array}{l}38 \pm 2 \\
44 \pm 3\end{array}$ & $\begin{array}{l}39 \pm 3 \\
44 \pm 2\end{array}$ & $\begin{array}{l}41 \pm 2 \\
47 \pm 2\end{array}$ & $\begin{array}{l}39 \pm 3 \\
47 \pm 2\end{array}$ & $\begin{array}{l}42 \pm 3 \\
48 \pm 3\end{array}$ & $\begin{array}{l}43 \pm 3 \\
48 \pm 3\end{array}$ & $\begin{array}{l}41 \pm 2 \\
48 \pm 2\end{array}$ \\
\hline
\end{tabular}

Table II Amplitudes of oesophageal peristaltic waves

\section{GARDIAC SPHINGTER}

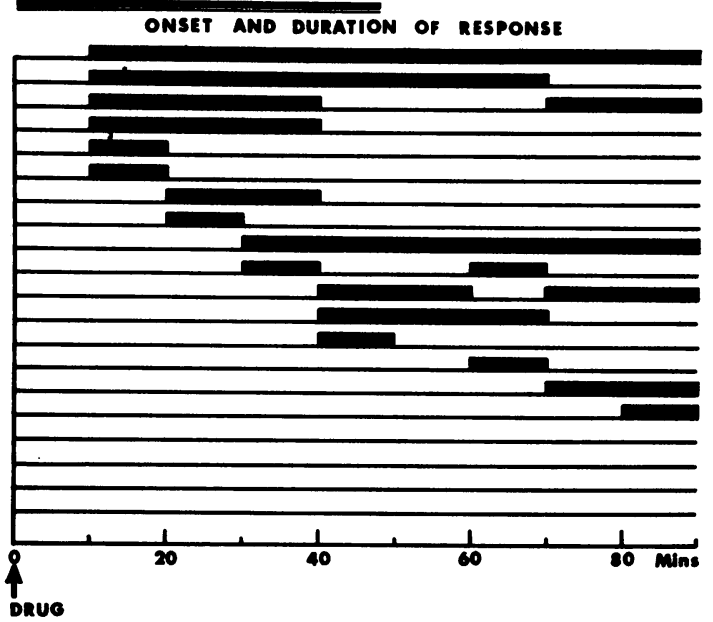

Fig 3 Duration and onset of the 'response' of cardiac sphincter in individual patients. Thick bars indicate sphincteric pressures $\geqslant 100 \%$ above mean basal level.

from symptoms of gastrooesophageal reflux. The effect on the sphincter was observed in the majority of fasting patients 20 min after the drug was given. These changes are in line with effects of the drug which follow parenteral administration (Heitmann and Möller, 1970). and are potentially valuable in the management of heartburn and regurgitation.

Our data, however, do not provide direct evidence that the gastrooesophageal junction was made competent by metoclopramide, nor do they indicate how the effect of the drug may be modified by meals. Moreover, the response to metoclopramide was variable and although the cardiac sphincter was stimulated in most patients, the increase was greatest in those with initially high pressures. Similar findings have been reported during intravenous administration (Heitmann and Möller, 1970) and may set a limit to the efficacy of the drug. Experiments in vitro suggest that metoclopramide sensitized human alimentary muscle to acetylcholine (Eisner, 1968), although an additional mode of action on intramural nerves may also be present, at least in laboratory animals (Jacoby and Brodie, 1968; Bianchi, Beani, and Crema, 1967). The effects of metoclopramide are partially prevented by atropine (Eisner, 1968; Jacoby and Brodie, 1968), so that anticholinergic drugs should not be prescribed with it. Now that oral metoclopramide has been shown to exert a pharmacological action on the cardiac sphincter, its therapeutic value should be assessed in clinical trials.

We thank Mrs I. M. Prentice, Miss C. Schilling, and Mr A. G. Booker for the illustrations.

\section{References}

Bianchi, C., Beani, L., and Crema, C. (1970). Effects of metoclopramide on isolated guinea pig colon. 2. Interference with ganglionic stimulant drugs. Europ. J. Pharmacol., 12, 332-341.

Eisner, M. (1968). Gastrointestinal effects of metoclopramide in man. In vitro experiments with human smooth muscle preparations. Brit. med. J., 4, 679-680.

Heitmann, P., and Möller, N. (1970). The effect of metoclopramide on the gastro-esophageal junctional zone and the distal esopha. gus in man. Scand. J. Gastroent., 5, 620-626.

Jacoby, H. I., and Brodie, D. A. (1967). Gastrointestinal actions of metoclopramide. Gastroenterology, 52, 676-684. 